\title{
A Moralidade dos Cuidados Paliativos
}

\author{
Carlos Henrique Debenedito Silva \\ Hospital do Câncer IV - INCA. E-mail:chdsilva@ inca.gov.br
}

Vamos apresentar alguns artigos que permitem uma análise crítica da "proteção" deontológica do Código de Ética M édica na sua atual versão (resolução CFM no 1.246/88 de 08.01.88 publicada no D.0.U. de 26.01.88), cuja grande maioria dos 145 artigos que o compõem, tem na ordenação jurídica sua linha de enquadramento. N osso interesse é apontar a linha divisória, tênue, que se situa entre a legalidade e a moralidade do exercício médico, voltado para os Cuidados Paliativos. Isso quer dizer: caso o ato esteja no código, portanto legal, poderá ser realizado; caso contrário, não. Aí a Bioética pode entrar com suas ferramentas, para exercitar nossa capacidade de reflexão não conservadora, produto do pluralismo moral atual, fruto da evolução da sociedade. A Ética está codificada, enquanto a $\mathrm{M}$ oral (que é diferente de Ética), vista como moralidade, nos permite pensar sob conflitos que podem ser legalizados, codificados ou não. N ossa sociedade está mudando, progredindo, aberta a novos conceitos e novas argumentações.

Teremos que ter apenas o cuidado de não vermos na Bioética aquela que trará as respostas prontas, como fosse capaz de dar soluções mágicas nas áreas de sua atuação. Ela trabal ha com a legitimidade individualizada dos casos e obrigatoriamente nos remete a pensar com uma argumentação conceitual teórica de aplicação prática. O s protocolos clínicos, que em sua essência são coletivos, utilizando o consentimento livre e esclarecido, na sua fase inicial de análise pelos Comitês de Ética em Pesquisa, como documento de primeira abordagem pelo envolvimento de seres humanos, já se reporta à Bioética.

Acreditamos que atualmente o direito primordial que possa existir a todo o ser humano, seja viver em paz. Com isso queremos dizer que todos tenhamos Vida e Paz.

$\mathrm{N}$ a condição de um indivíduo se encontrar com sua saúde afetada, padecendo numa instituição especializada como o IN CA, decorrente de câncer avançado, quer numa enfermaria ou no setor de cuidados intensivos, já em condições de irreversibilidade de cura, cabe perguntar se estaremos cuidando da sua vida ou prolongando a agonia que pode levá-lo à sua morte. Seu futuro poderá depender de medidas extraordinárias, seja por introdução de novas drogas, outros procedimentos invasivos, ou de tecnologia sofisticada. $\mathrm{N}$ a fase terminal, qualidade e quantidade de vida têm interpretações importantes.

Entre os artigos deontológicos da ordem médica (do grego déontos, 'o que é obrigatório, necessário', + logia, 'estudo, que trata') destacados para que utilizemos argumentos da Bioética, que poderão nortear nosso exercício da prática diária por outro prisma temos:

\section{Capítulo I - Princípios Fundamentais}

Art. $1^{\circ}$ - A M edicina é uma profissão a serviço da saúde do ser humano e da coletividade e deve ser exercida sem discriminação de qualquer natureza.

Art. $2^{\circ}$ - 0 alvo de toda a atenção do médico é a saúde do ser humano, em benefício da qual deverá agir com 0 máximo de zelo e o melhor de sua capacidade profissional.

Art. $6^{\circ}$ - 0 médico deve guardar absoluto respeito pela vida humana, atuando sempre em benefício do paciente. Jamais utilizará seus conhecimentos para gerar sofrimento físico ou moral, para o extermínio do ser humano, ou para permitir e acobertar tentativa contra sua dignidade e integridade.

Q uanto ao direito à $V$ ida, é inegável sua legitimidade, tanto dos pacientes, quanto para eles. Lutamos em todas as instâncias por ela. Cobramos dos gestores de saúde eqüidade no acesso aos tratamentos, condições mais favoráveis de trabalho, entre tantas ações. A beneficência da M edicina é princípio básico e inequívoco da profissão. A constante atualização do conhecimento médico e a utilização do desenvolvimento técnico-científico é parte de 
nossa responsabilidade em prol dos pacientes e lida no seguinte artigo:

Art. $5^{\circ}$ - 0 médico deve aprimorar continuamente seus conhecimentos e usar o melhor do progresso científico em benefício do paciente.

A profundando as discussões bioéticas, como morrer é uma certeza indubitável da nossa vida, temos que discutir noções de uma vida boa (como pretendia Arsitóteles), para termos uma boa vida e também noções de uma morte boa, para termos uma boa morte. Isso nos remete diretamente à Eutanásia, termo de origem grega, que ao longo dos tempos tem significados diferentes em realidades diferentes:

- morte sem sofrimento físico;

- morte que se provoca voluntariamente (recém-nascidos deficientes, de quem se poderá imaginar portadores de uma vida diminuída);

- morte sem dor (morte em estado de graça);

- morte por solicitação do próprio enfermo, da sua família, do médico ou do Estado;

- ajuda de morte ao suicída (consumação de seu propósito);

- ajuda de morte ao ancião (presunção de vida indigna);

- morte decorrente da recusa voluntária em começar ou manter tratamento inútil;

- morrer bem, direito à própria morte (morte apropriada, morte digna ou morte doce).

$\mathrm{N}$ a prática, decorrente do significado que se dê à "eutanásia", pode-se interpretála como um crime ou um ato misericordioso. $\mathrm{N}$ ão se deve rotulá-la como mais inócua do que é, posição que propicia aceitação social, nem relegá-la a plano secundário, pois como eixo central tem-se que, por ela, um ser humano oferece a morte a outro. D iante desta variedade de sentidos, vamos ficar com o enunciado, de "morrer bem, aquele que morreu bem", para algumas reflexões. Considerando a participação de um homem na morte do outro, com o intuito de evitar sofrimento, ou por considerar que falte, à vida deste, qualidade mínima para merecer o adjetivo de "digna", poderá ser considerada, a eutanásia uma forma de homicídio. $\mathrm{H}$ avendo participação do agente, estaremos diante da eutanásia ativa, quer por desejo voluntário ou não do doente, considerada então, involuntária. D e outra forma, por omissão da atenção médica, será chamada eutanásia passiva. Sob qualquer dessas atuações estará o profissional de saúde fora da lei, conforme lembram os seguintes artigos:

\section{C apítulo III - Responsabilidade Profissional}

Art 320 - I sentar-se de responsabilidade de qualquer ato profissional que tenha praticado ou indicado, ainda que este tenha sido solicitado ou consentido pelo paciente ou seu representante legal.

\section{Capítulo V - Relação com Pacientes e Familiares}

Art 660 - Utilizar, em qualquer caso, meios destinados a abreviar a vida do paciente, ainda que a pedido deste ou de seu responsável legal.

O Código de Ética M édica traz um artigo que nos remete à dualidade dos direitos e deveres, dos médicos, tendo à sombra o Código Civil:

\section{C apítulo II - D ireitos do M édico}

Art 210 - Indicar o procedimento adequado ao paciente, observadas as práticas reconhecidamente aceitas e respeitando as normas legais vigentes no país.

Entende-se por procedimento adequado aquele em que o médico computa que valores? A rotina do serviço onde trabalha? A limitada oferta de drogas padronizadas por custo ou por indicação? A argumentação do que é mais resolúvel? A conjunção do conhecimento científico com argumentações bioéticas?

Talvez a única brecha no Código de Ética que permita ao médico atuar libertando-se das amarras deontológicas seja 0 artigo número 28, pois poderá dar razão a outros critérios:

Art 28 - Recusar a realização de atos médicos que, embora permitidos por lei, sejam contrários aos ditames de sua consciência.

Logo a seguir, volta o Código a puxar as rédeas do controle, quando lembra ao médico de seu enquadramento, em três artigos:

\section{C apítulo III - Responsabilidade Profissional}

Art 29 - Praticar atos profissionais danosos ao paciente, que possam ser caracterizados como imperícia, imprudência ou negligência.

\section{C apítulo V - Relação com Pacientes e Familiares}

Art 57ㅇ - Deixar de utilizar todos os meios disponíveis de diagnóstico e tratamento a seu alcance em favor do paciente.

Art 610 - Abandonar paciente sob seus cuidados.

$\S 2^{\circ}$ - Salvo por justa causa, comunicada ao paciente ou ao a seus familiares, o médico não pode abandonar 0 
paciente por ser este portador de moléstia crônica ou incurável, mas deve continuar a assisti-lo ainda que apenas para mitigar o sofrimento físico ou psíquico.

O s defensores da sacralidade da vida, com a utilização de meios extraordinários, principalmente por intermédio das novas tecnologias, nos pacientes fora de chances terapêuticas, são por muitos responsabilizados como defensores da distanásia. A utilização de toda a tecnologia médica no prolongamento da morte, ou mais precisamente do processo de morrer, configura um caminho penoso e inútil. Importante é caracterizar bem o sentido dado a esse processo para embasar a reflexão ética.

0 antagonismo entre eutanásia e distanásia coloca a aproximação da morte em campos opostos. Os que pregam a eutanásia o fazem por uma qualidade da morte, enquanto os que defendem a quantidade da vida até o fim, exercem a distanásia, igualmente referida como futilidade ou obstinação terapêutica.

No passado, o papel desempenhado pelo médico, de acompanhar o paciente na fase avançada da doença tinha por finalidade aliviá-lo da dor e do sofrimento para aumentar o conforto de seus últimos dias. Q uando, a partir da segunda metade do século XX, o desenvolvimento técnico-científico trouxe melhorias no atendimento das pessoas doentes, apresentou à morte um novo enfoque. Esta passou a ser o inimigo número um a ser vencido ou escondido. Este paradigma técnico-científico justifica o prolongamento da distanásia pelo valor absoluto que se atribui à vida humana. Todos sabemos que os médicos, na grande maioria, evitam falar de morte, além de sexo, com seus pacientes.

A introdução ou manutenção de intervenções terapêuticas inúteis, que tem como termos assemelhados: medical futility, l'acharnement thérapeutique, ensañamiento ou encarnizamiento terapéutico, impedem a pessoa de alcançar em paz sua morte como fim natural de sua vida. Trata-se da perpetuação da tenacidade do tratamento na manutenção da vida, sem levar em conta a validade no benefício à qualidade da vida que resta a este doente. Com essa atitude, alongar o tempo de vida pela manutenção dos sinais vitais de uma pessoa que se encontre na fase avançada de sua doença, não leva em conta a constatação da terminalidade estar próxima, com o emprego de critérios objetivos de prognosticação, mediante dosagens séricas de alguns elementos, exames de imagem, índice de performance status, por exemplo, que demonstrem a falência progressiva e múltipla de órgãos, permitindo-se perguntar, então, até quando se deve investir nessa situação.

M ais recentemente, a moralidade dos Cuidados Paliativos veio resgatar os princípios da qualidade de vida, controle da dor e diminuição do sofrimento imposto ao doente, que, pelo avanço da patologia que o acomete, sai da área de tratamento curativo. Como atualmente se entende por saúde o bem-estar global, abrem-se à discussão outras questões no tratamento do doente terminal. N essa fase, a interpretação de saúde como bem-estar físico, psicológico, social e espiritual, permite ajustes na valoração que se atribui à vida humana, trazendo a perspectiva da morte não como doença a curar, mas sim, parte integrada da vida. Pelo paradigma comercial, que visa lucro para as empresas e para al guns médicos, a utilização de todo 0 aparato tecno-científico tem, na lógica empresarial, apoio na ética humanista, igualmente pelo valor da vida, bem entendido, pelo que se paga por ela, enquanto houver recursos para tal.

Cuidado Paliativo não é um tratamento alternativo e sim complementar e vital no manuseio total do ser humano ${ }^{1 .}$ $\mathrm{O}$ atual entendimento dos Cuidados Paliativos se deu com a fundação do Saint Christopher's H ospice, em Londres, em 1967, pela D rạ Cicely Saunders, onde defendia uma atuação que garante até hoje:

- qualidade de cuidados para o paciente e familiares;

- variedade de serviços para proporcionar um ótimo cuidado independente do paciente estar em casa, no hospital ou requerer um especialista;

- educação, aconselhamento e auxílio para outros profissionais;

- prática baseada em evidência;

- pesquisa e avaliação.

$\mathrm{N}$ a medicina paliativista, quando promovemos, através do atendimento multidisciplinar, o respeito à integridade

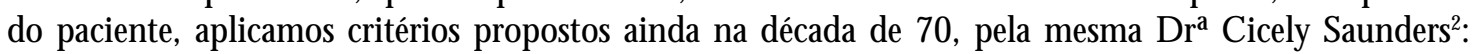

- ser mantido sem dor tanto quanto possível;

- receber cuidados contínuos, não sendo abandonado;

- dar ao paciente ciência para que tanto quanto possível tome decisões da sua vida;

- ser respeitado e ouvido como pessoa em seus medos, pensamentos, sentimentos, valores e esperanças;

- poder escolher onde deseja morrer.

$\mathrm{O}$ Instituto Nacional de Câncer também tem seu hospice, situado no $\mathrm{H}$ ospital de Câncer IV, onde recebe os pacientes oriundos das U nidades I, II e III, acompanhados de seus familiares, tratando-os igualmente com respeito, dignidade nas suas fraquezas, ouvindo-os em seus temores, numa abordagem multidisciplinar. A eles são proporcionados todos os cuidados no atendimento, quer na unidade de pacientes externos, no ambulatório ou na 
enfermaria, preparando-os, se possível, para retorno a seus próprios lares. U ma das etapas importante no papel da equipe de atendimento é a identificação de parentes, preferencialmente, que serão preparados para desempenhar o papel de cuidador domiciliar. Essa atenção no domicílio será integrada com as visitas realizadas pelas unidades volantes, que em periodicidade semanal ou quinzenal, propiciarão uma constante e ativa avaliação, caso a caso. As equipes de visita domiciliar atualmente acompanham em torno de 880 pacientes em internação domiciliar, número que somado aos dos pacientes internados na unidade hospitalar e em acompanhamento ambulatorial, alcança cerca de 600 pessoas/mês. Isso demonstra a magnitude do trabalho humanizado lá desenvolvido.

\section{Referências}

1. Full C. In: Full C, Carter Y, Woof R, editors. Handbook of palliative care. O xford: Blackwell Science; 1998. $p$. $1-11$.

2. Twycross RG. M ud and stars. The report of a working party on the impact of hospice experience on the church's ministry of healing. Oxford: Sobell Publications; 1991. 